\title{
Planning strategies to address operational and price uncertainty in biodiesel production
}

Carla Caldeira* ${ }^{\mathrm{a}, \mathrm{b} 1}$, Omar Swei $^{\mathrm{c}}$, Fausto Freire ${ }^{\mathrm{a}}$, Luís Dias ${ }^{\mathrm{b}, \mathrm{d}}$, Elsa A. Olivetti ${ }^{\mathrm{e}}$, Randolph Kirchain ${ }^{\mathrm{f}}$

${ }^{a}$ ADAI-LAETA Department of Mechanical Engineering, University of Coimbra, Polo II, Rua Luís Reis Santos, 3030-788 Coimbra, Portugal

Email: caldeira.carla@gmail.com; fausto.freire@dem.uc.pt

${ }^{\mathrm{b}}$ INESC-Coimbra University of Coimbra, Polo II, Rua Sílvio Lima 3030-290 Coimbra, Portugal

${ }^{\mathrm{c} D e p a r t m e n t ~ o f ~ C i v i l ~ E n g i n e e r i n g, ~ T h e ~ U n i v e r s i t y ~ o f ~ B r i t i s h ~ C o l u m b i a, ~ C E M E ~ 2004 C, ~} 6250$ Applied Science Lane, Vancouver, BC V6T 1Z4, Canada

Email:oaswei@civil.ubc.ca

${ }^{\mathrm{d} C e B E R}$ and Faculty of Economics, University of Coimbra, Av Dias da Silva 165, 3004-512 Coimbra, Portugal

Email: lmcdias@fe.uc.pt

${ }^{\mathrm{e}}$ Department of Materials Science \& Engineering, Massachusetts Institute of Technology, 77 Massachusetts, Cambridge, MA 02139, USA

Email: elsao@mit.edu

${ }^{\mathrm{f}}$ Materials Systems Laboratory, Massachusetts Institute of Technology, 77 Massachusetts Avenue, Cambridge, MA 02139, USA

Email: kirchain@mit.edu

\footnotetext{
${ }^{1}$ Current affiliation: European Commission, Joint Research Center, Directorate of Sustainable Resources,
} Bioecomomy Unit, Ispra, Italy 


\begin{abstract}
The use of low-cost feedstocks such as waste cooking oils has gained prominence in biodiesel production due to its potential economic and environmental advantages. Since these feedstocks are derived from multiple sources, its compositional variability has led to quality concerns that may significantly limit its utilization. One potential strategy to address this concern is to use stochastic blending models to optimize the mixing of secondary and primary oils (e.g., palm, canola, or soya). In this paper, we present a stochastic blending model that embeds a second, key source of uncertainty: the future price of feedstocks, a topic of tremendous concern for producers. The stochastic blending model embeds a chance-constrained formulation to account for compositional variability and uses time-series methods to address feedstock price uncertainty. The model was developed to support production-planning decisions to minimize cost and cost variation in biodiesel production. We demonstrate that the proposed approach is useful for determining an optimal planning of feedstock acquisition, blending and storage in order to minimize the risks associated with feedstock price fluctuations. Results show that addressing the compositional uncertainty via the chance-constrained formulation will allow for the use of waste cooking oil in biodiesel blends without compromising their technical performance.
\end{abstract}

Keywords: compositional uncertainty, feedstock blending, forecast models, optimization, time series analysis, waste cooking oil 


\section{Introduction}

In the late 1990s, biofuels emerged as a strategy to increase revenue for farmers, reduce greenhouse gas emissions, and improve energy independence [1]. However, what seemed to be the solution for such critical issues has become a controversial topic; demand for biofuel feedstocks may have increased food prices [2,3] and their environmental benefits are ambiguous [4,5]. This dilemma makes it clear that producers and governmental agencies must make smarter feedstock selection decisions in order to achieve their ambitious goals, particularly given that feedstocks are responsible for the majority of biofuel producer costs (about 85\%) [6] and lifecycle greenhouse gas emissions (about 70 to $80 \%$ ) [7].

This paper focuses on two key dynamics that must be considered to improve biofuel feedstock decisions: (1) the shift to novel, alternative feedstocks and (2) feedstock price volatility. The European Commission recently published Directive 2015/1513 recommending to cap the use of food crop-based feedstocks and encourage the development of alternative feedstocks that do not compete with foods $[8,9]$. In the United States, the Environmental Protection Agency has also been exploring a lower cap on the use of crop-based feedstocks [10]. Caps like these will add pressures on biodiesel producers and limit their available options to, on average, lower quality (yet higher variability) alternative feedstocks [11]. Several studies suggest that feedstocks from residues such as waste cooking oils (WCO) may simultaneously reduce production costs [12] and environmental impacts $[13,14]$. However, the technical characteristics of residue-derived feedstocks (RDFs) are highly variable and may lead to operational difficulties $[15,16]$.

The volatility associated with the price of feedstocks conventionally used in biodiesel production is another challenge facing producers [17]. Since current demand for RDFs including WCO is relatively small, one would expect particularly high price volatility in the future [18]. To move forward with such RDFs in production, suppliers need high-fidelity models that explicitly account for price volatility, which may cause producers to be particularly conservative in planning production. 
Based on the described challenges facing producers in their operational decisions, this paper explores novel feedstock-selection algorithms that can be used in biodiesel production planning to increase its cost effectiveness. These algorithms will assess the value of the use of RDFs in biodiesel blends and hedging feedstock purchases (i.e., purchases made ahead of time of use) in a context where both feedstock quality and price are uncertain.

In this research, quality variability is addressed using stochastic blending models (chanceconstrained (CC) formulation) to identify the lowest cost combination of low quality RDFs and conventional feedstocks used worldwide for biodiesel production (e.g., virgin oils such as palm, canola and soya). The CC method has been shown to identify blending strategies that increase secondary (i.e. recycled) material utilization while controlling variation in the finished good, allowing secondary producers to explicitly control the risk of quality variation in incoming raw materials [19]. Moreover, CC can increase potential heterogeneous material use (i.e., lower cost material) through raw materials diversification and, consequently, reduce costs [20]. Gülsen et al. [21] and Olivetti et al. [22] developed a CC blend optimization model that explicitly considers the inherent uncertainty present in the feedstock properties of conventional vegetable oils commonly used for biodiesel production. Results show that feedstock diversification can help control costs and ensure fuel quality by spreading the risk of price volatility across multiple feedstocks [21]. In addition to achieving cost reductions, blending can also be used to manage greenhouse gas emissions uncertainty characteristics of biodiesel [22]. Although conventional feedstocks present compositional variability, this is not as high as the variability observed in residue material such as WCO, which may limit its market potential [23]. As a follow up of Gülsen et al. [21] and Olivetti et al. [22] approach, the CC biodiesel blending model is applied in this work focused on the use of RDFs (WCO).

The other aspect considered in this research is the variability in feedstock price. Optimization models that consider price uncertainty can be found in the literature applied to a plethora of areas such as electricity [24], metal [25], fleet replacement [26], chemical industry [27], supply chain 
network [28] or forestry [29] using different approaches. A widely used approach to deal with price volatility is two stage stochastic programming with recourse. Examples include to determine the optimum production plans for a petroleum supply chain that minimize the risks due to fluctuations in market conditions [30]; to deal with variability in performance requirements in optimal midterm refinery planning [31]; to explicitly account for uncertainty in spot market prices of raw materials and the predictability of demand response models (DRM) applied to a chemical production network [27]; and to determine product prices and design an integrated supply chain operations plan under demand uncertainty [32]. Other approaches use: geometric Brownian motion (GMB) to model price behavior over time to decide optimal crude oil procurement and amount of oil products to produce [33]; fuzzy set theory to address uncertainty in electricity price forecasting in the optimization of capacity of distribution generation sources and operational strategy in microgrids [34]; or, the Markowitz Mean-Variance (MMV) model to determine the optimal planning at a refinery [31].

In the biofuel area, some studies address price uncertainty. Marvin et al. [35] analyzed the influence of variability of several economic parameters, including the feedstock cost of biomass, assuming a variation of each parameter at a time and using Monte Carlo simulation to analyze the effects of each parameter on the Net Profit Value (NPV) of proposed biorefineries. Dal-Mas et al. [36] built probability functions for corn purchase cost and fuel ethanol market price, that were then discretized into the vectors of scenarios. The model is used to assess the influence of these factors in the profitability of the biorefinary. Also the work done by Giarola [37] followed a scenario approach to address uncertainty associated with biomass costs. The model maximizes profit and uses a parameter that represents the decision-makers' attitude towards financial risk and also a weighing factor to model the trade-off between the expected profit and GHG emissions. Mazzeto et al. [38] used scenario modelling to capture the uncertainty of the corn and ethanol prices using forecasted prices. The model optimizes the NPV of the whole supply chain during its entire operative life. In the work done by Osmani and Zhang [39] uncertainty in prices, demand and supply are addressed using two stage stochastic programming. The model is a multi-objective 
model that maximizes the annual profit of an integrated dual-feedstock lignocellulosic-based bioethanol supply chain and minimizes carbon emissions. Santibanez-Aguilar et al [40] addresses raw material price uncertainty in the design of biorefinery supply chains by the stochastic generation of scenarios using the Latin Hypercube method followed by the implementation of the Monte-Carlo method. Zhang et al. [41] considers the uncertainty of biodiesel price using a min-max approach, addressing uncertainty by guaranteeing the feasibility and optimality of the solution against all instances of the parameters within the uncertainty set in an attempt to design a robust supply chain considering WCO suppliers, integrated bio-refinery and demand zone. Bairamzadeh et al. [42] presents a hybrid robust optimization model to handle multiple types of uncertainty, including randomness, epistemic and deep uncertainties in the biofuel supply chain network design and planning problem. Also applied to supply chain design optimization, in this case of biogas, the work presented by Khishtanda [43] addresses the price of biomass uncertainty using fuzzy chanceconstrained programming.

The gap identified in the literature and that motived the research presented in this paper was the lack of a model that would address feedstock price uncertainty in a dynamic approach using feedstock price forecast models to optimize blends for biodiesel production, considering simultaneously the uncertainty of the feedstocks composition. The approach presented in this paper is innovative as it presents novel feedstock-selection algorithms that combine price forecast models to address price uncertainty with stochastic approaches that address compositional uncertainty. The model allows to consider the use of RDFs in the blending without compromising the technical quality of the biodiesel. Moreover, the dynamic nature of the price uncertainty modelling extends the scope of the analysis further than just having fixed recipes. Technical, cost and cost variation performance metrics were used to investigate and interpret the behavior of the proposed approach in order to answer the following research questions: (1) Can WCO be incorporated in blends for biodiesel production without compromising the biodiesel technical performance? (2) What are the economic benefits of using WCO in the blends? (3) Can production cost variation be reduced by 
planned hedging purchases informed by forecasted feedstock prices? (4) Does such an approach makes WCO more or less attractive? By answering these questions, we intend to provide biodiesel producers information and tools to support feedstock optimization, reducing biodiesel production costs and cost variation.

This innovative approach is a significant contribution to (1) the optimal use of energy resources, by providing a way to use higher quantities of RDF's without compromising the product final quality, and (2) to the development of sustainable energy systems.

\section{Material and methods}

\subsection{Stochastic model to address biodiesel feedstock composition and price uncertainty}

The model developed determines the optimal feedstock purchase and use plan that minimizes costs by identifying both (1) the quantities of each available feedstock to buy, store and use and (2) the specific combination of feedstocks to blend in a biodiesel production plant, in face of two types of uncertainty: (a) feedstock compositional uncertainty and (b) feedstock price uncertainty. The former type of uncertainty influences the constraints of the model and is addressed using chanceconstrained programming. The latter influences the coefficients of the objective function and is addressed by adding a term to the objective function to reflect the uncertainty around future prices. A description of the approach followed to address each type of uncertainty is presented in subsections 2.1.1 and 2.1.2. The full model formulation is presented is sub-section 2.1.3. 


\subsubsection{Chance-constrained (CC) to address compositional uncertainty}

The chance-constrained (CC) formulation was first presented by Charnes and Cooper [44] for a logistics planning model with uncertain flows. The CC formulation allows the user to select a confidence level at which a constraint must be complied; it adds flexibility to the model reflecting the reality under consideration $[45,46]$. Deterministic constraints typically found in optimization formulations as shown in Equation 1, where $a_{i}$ is the stochastic parameter, $x_{i}$ is the decision variable and $b$ is the constraint level, are replaced by nonlinear versions as shown in Equation 2 . The nonlinear versions incorporate statistical characteristics of the problem assuming that $a_{i}$ is normally distributed parameter, $\mathrm{a}_{\mathrm{i}} \sim \mathrm{N}\left(\mu_{i}, \sigma_{i}^{2}\right)$ and all $a_{i}$ are independent. Considering Gaussian distributions for the stochastic parameter, $K_{1-\alpha}$ is the test coefficient usually denoted as a $\mathrm{z}$-value corresponding to the chosen confidence value level. A detailed explanation about the CC formulation is provided in supplementary material (Section 1).

$$
a_{i} x_{i} \leq b
$$

$$
\sum_{i=1}^{N} \mu_{i} x_{i}+K_{1-\alpha} \sqrt{\sum_{i=1}^{N} \sigma_{i}^{2} x_{i}^{2}} \leq b
$$

\subsubsection{Price projection model and storage purchase optimization to address price uncertainty}

To address price uncertainty, a stochastic model that uses forecasted feedstocks prices was developed to inform purchasing and holding decisions. The model uses both current and forecasted feedstock prices and information on current inventory to decide the quantities to blend, buy and store in each period (in our model, one period represents a single month). The decision in each period is made based on actual prices for that period and forecasted prices for the next 2 periods. For example, to decide what to buy (denoted as Quantity to buy, or $Q B$ ), store (denoted as Quantity to store, or $Q S$ ), and use (denoted as Quantity to use, or $Q U$ ), in period 1, the actual prices in 1 and forecasted prices for periods 2 and 3 are used. Then, to decide what to buy, store and use in period 
2, the prices for period 2 are replaced by the actual prices and predicted prices for periods 3 and 4 are used. The optimization is repeated for $W$ time periods. The modelling approach is illustrated in Fig. 1.

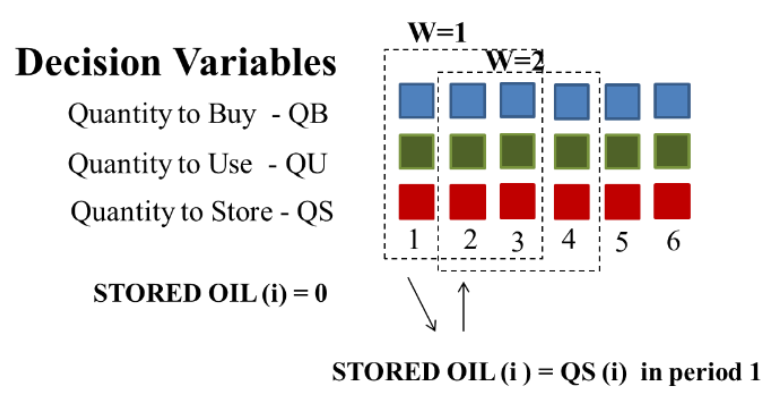

Fig. 1 Schematic representation of the modelling approach

\subsubsection{Model formulation}

The CC constraints and the recourse planning model were combined to create a dynamic model to identify the quantity of each feedstock $i$ to buy in period $p\left(Q B_{i, p}\right)$, store $\left(Q S_{i, p}\right)$ and use $\left(Q U_{i, p}\right)$ as previously explained in Section 2.1 (Fig. 1). The objective is to minimize the cost function, $Z$ (Equation 3), which comprises three terms: (1) the cost of the feedstock, given by the quantity of each feedstock to purchase $\left(Q B_{i, p}\right)$ and the actual feedstock price in time period $p\left(P_{i, p}\right)$; (2) the storage cost, given by the quantity stored $\left(Q S_{i, p}\right)$ storage cost $(S t C o s t)$; and (3) a penalty term for the use of feedstocks that increase future price uncertainty. Parameter $\alpha$ is the risk tradeoff parameter associated with price uncertainty. Specifically, $\alpha$ creates a penalty within the objective function for price risk (uncertainty); a higher $\alpha$ penalizes risk more. Theoretically, $\alpha$ can vary over the entire range of positive real numbers $[0, \infty]$ to generate a set of feasible decisions that have minimum cost for a given level of risk. However, in practice it was verified that after a certain value (specifically, $\alpha=10$ ) no changes in the total cost and cost variation were observed. This model will allow analyzing two strategic quantities that influence producer price risk: the extent of available storage capacity and the relative weight placed on price risk (i.e. compared to the expected value of price). 
The model is subject to demand and supply constraints (Equation 4 and Equation 5); since the goal is to analyze the proportions of each feedstock in the blend, demand is set equal to 1 and there are no supply limitations. Equations 6-9 list the storage constraints, in which we consider a storage capacity of $20 \%$ of production.

Technical constraints (defined as Equations 10 and 11) were built according to the CC formulation (Equation 2) and based on prediction models that relate the chemical composition (fatty acids, $F A$ ) of the vegetable oils and biodiesel properties [23,47]. Prediction models based on the chemical composition of the vegetable oils were found for the following biodiesel properties: density (Den) [48], cetane number $(C N)$ [49], cold filter plugging point $(C F P P)$ [50], iodine value $(I V)$ [51]and oxidative stability $(O S)[52]$. Although other biodiesel parameters are critical for biodiesel producers, the focus of this model is to specifically address properties that are directly related to the fatty acid composition. These models are presented and discussed by Caldeira et al. [53,54], which concluded that the derived results from the prediction models are in agreement with measurement values found in the literature. These models were used as technical constraints in the optimization model and the constraint threshold was based on the European Standard EN 14214 that define the FAME requirements for diesel engines. The chemical composition information (average and standard deviation) used in the model was adopted from Hoekman et al.[23]. $\beta$ is the test coefficient (z-value) corresponding to the chosen confidence value level and is determined by the user. The nomenclature (Table 1) and mathematical formulation of the problem are presented below. The model was implemented in GAMS 24.4.2 [55] and the problem is solved using the non-linear solver CONOPT [56]

Table 1 Biodiesel blending optimization problem nomenclature

\begin{tabular}{cll}
\hline Indices and sets & $i \in \mathrm{I}$ & $\mathrm{I}=\{$ soya, canola, palm, WCO $\}$, feedstock oils \\
$\mathrm{p} \in \mathrm{P}$ & $\mathrm{P}=\{1,2,3\}$, periods \\
$\mathrm{j} \in \mathrm{J}$ & $\mathrm{J}=\{1,2, \ldots, 18\}$, Fatty Acids (FA) index \\
$1 \in \mathrm{L}$ & $\mathrm{L}=\{$ DenLB, CN, OS $\}$, set of properties with lower bound
\end{tabular}


$\mathrm{m} \in \mathrm{M} \quad \mathrm{M}=\{$ DenUB, IV, CFPP $\}$, set of properties with upper bound

\begin{tabular}{|c|c|c|}
\hline \multirow[t]{16}{*}{ Parameters } & $P_{i, p}$ & Price of feedstock $\mathrm{i}$ in period $\mathrm{p}$ \\
\hline & StCost & Storage cost \\
\hline & $\sigma \mathrm{fc}_{\mathrm{i}, \mathrm{p}}$ & Standard deviation of the price of feedstock $i$ in period $p$ \\
\hline & $\mathrm{D}$ & Demand \\
\hline & $S_{i, p}$ & Supply of feedstock i in period $\mathrm{p}$ \\
\hline & $\operatorname{StCap}_{i}$ & Storage Capacity of feedstock i \\
\hline & $\overline{\mathrm{q}_{1, j}}$ & Average quantity (\%) of FA-j in feedstock $\mathrm{i}$ \\
\hline & $\sigma_{\mathrm{i}, \mathrm{j}}$ & Standard deviation of the quantity $(\%)$ of FA-j in feedstock $i$ \\
\hline & PropCoef $_{l, j}$ & Coefficient of FA-j in the prediction model for property 1 \\
\hline & PropCoef $_{m, j}$ & Coefficient of FA-j in the prediction model for property $\mathrm{m}$ \\
\hline & PropConst $_{1}$ & Constant in the prediction model for property 1 \\
\hline & PropConst $_{\mathrm{m}}$ & Constant in the prediction model for property $\mathrm{m}$ \\
\hline & $\operatorname{PropGT}_{l}$ & Threshold for property 1 \\
\hline & PropLT $_{m}$ & Threshold for property $\mathrm{m}$ \\
\hline & $\alpha$ & Risk tradeoff parameter \\
\hline & $\beta$ & Test coefficient for normal distribution, one tailed \\
\hline \multirow[t]{3}{*}{ Variables } & $\mathrm{QB}_{\mathrm{i}, \mathrm{p}}$ & Quantity of feedstock i to buy in period $p$ \\
\hline & $\mathrm{QU}_{\mathrm{i}, \mathrm{p}}$ & Quantity of feedstock i to use in the blend in period $p$ \\
\hline & $\mathrm{QS}_{\mathrm{i}, \mathrm{p}}$ & Quantity of feedstock i to store in period $p$ \\
\hline
\end{tabular}

$\underline{\text { Objective function }}$

Minimize: $\mathrm{Z}=\sum_{\mathrm{p} \in \mathrm{P}} \sum_{\mathrm{i} \in \mathrm{I}} \mathrm{P}_{\mathrm{i}, \mathrm{p}} \mathrm{QB}_{\mathrm{i}, \mathrm{p}}+\sum_{\mathrm{p} \in \mathrm{P}} \sum_{\mathrm{i} \in \mathrm{I}} \mathrm{StCost}_{\mathrm{QS}} \mathrm{i,p}+\alpha \sqrt{\sum_{\mathrm{p} \in \mathrm{P}} \sum_{\mathrm{i} \in \mathrm{I}} \sigma \mathrm{fc}_{\mathrm{i}, \mathrm{p}}{ }^{2} \mathrm{QB}_{\mathrm{i}, \mathrm{p}}{ }^{2}}$

$\underline{\text { Demand and Supply constraints }}$

$$
\begin{gathered}
\sum_{\mathrm{i} \in \mathrm{I}} \mathrm{QU}_{\mathrm{i}, \mathrm{p}}=\mathrm{D} \quad \forall_{\mathrm{p} \in \mathrm{P}} \\
\mathrm{QB}_{\mathrm{i}, \mathrm{p}} \leq \mathrm{S}_{\mathrm{i}, \mathrm{p}} \quad \forall_{\mathrm{p} \in \mathrm{P}}, \forall_{\mathrm{i} \in \mathrm{I}}
\end{gathered}
$$

$\underline{\text { Storage constraints }}$ 


$$
\begin{gathered}
\mathrm{QB}_{\mathrm{i}, 1}=\left(\mathrm{QS}_{\mathrm{i}, 1}-\mathrm{QS}_{\mathrm{i}, 0}\right)+\mathrm{QU}_{\mathrm{i}, 1} \quad \forall_{\mathrm{i} \in \mathrm{I}} \\
\mathrm{QB}_{\mathrm{i}, 2}=\left(\mathrm{QS}_{\mathrm{i}, 2}-\mathrm{QS}_{\mathrm{i}, 1}\right)+\mathrm{QU}_{\mathrm{i}, 2} \quad \forall_{\mathrm{i} \in \mathrm{I}} \\
\mathrm{QB}_{\mathrm{i}, 3}=\left(\mathrm{QS}_{\mathrm{i}, 3}-\mathrm{QS}_{\mathrm{i}, 2}\right)+\mathrm{QU}_{\mathrm{i}, 3} \quad \forall_{\mathrm{i} \in \mathrm{I}} \\
\mathrm{QS}_{\mathrm{i}, \mathrm{p}} \leq \mathrm{StCap}_{\mathrm{i}} \forall_{\mathrm{p} \in \mathrm{P}}, \forall_{\mathrm{i} \in \mathrm{I}}
\end{gathered}
$$

\section{$\underline{\text { Technical Constraints }}$}

$$
\begin{aligned}
& \sum_{j \in J}\left(\operatorname{PropCoef}_{1, j} \sum_{i \in I} \mathrm{QU}_{\mathrm{i}, \mathrm{p}} \overline{\mathrm{q}_{\mathrm{l}, \mathrm{j}}}\right)+\operatorname{PropConst}_{1}-\beta \sqrt{\sum_{\mathrm{j} \in \mathrm{J}} \operatorname{PropCoef}_{\mathrm{l}, \mathrm{j}}{ }^{2} \sum_{\mathrm{i} \in \mathrm{I}} \mathrm{QU}_{\mathrm{i}, \mathrm{p}}{ }^{2} \sigma_{\mathrm{i}, \mathrm{j}}^{2}} \geq \operatorname{PropGT}_{\mathrm{l}} \quad \forall_{\mathrm{p} \in \mathrm{P}}, \forall_{\mathrm{l} \in \mathrm{L}} \\
& \sum_{\mathrm{j} \in \mathrm{J}}\left(\operatorname{PropCoef}_{\mathrm{m}, \mathrm{j}} \sum_{\mathrm{i} \in \mathrm{I}} \mathrm{QU}_{\mathrm{i}, \mathrm{p}} \overline{\mathrm{q}_{\mathrm{i}, \mathrm{j}}}\right)+\text { PropConst }_{\mathrm{m}}+\beta \sqrt{\sum_{\mathrm{j} \in \mathrm{J}} \operatorname{PropCoef}_{\mathrm{m}, \mathrm{j}}{ }^{2} \sum_{\mathrm{i} \in \mathrm{I}} \mathrm{QU}_{\mathrm{i}, \mathrm{p}}{ }^{2}{ }^{2}{ }_{\mathrm{i}, \mathrm{j}}} \leq \operatorname{PropLT}_{\mathrm{m}} \forall_{\mathrm{p} \in \mathrm{P}}, \forall_{\mathrm{m} \in \mathrm{M}} \\
& \mathrm{QB}_{\mathrm{i}, \mathrm{p}} \geq 0 ; \mathrm{QS}_{\mathrm{i}, \mathrm{p}} \geq 0 ; \mathrm{QU}_{\mathrm{i}, \mathrm{p}} \geq 0 \quad \forall_{\mathrm{p} \in \mathrm{P}}, \forall_{\mathrm{i} \in \mathrm{I}}
\end{aligned}
$$

\subsection{Price forecasting model}

Feedstock prices are forecasted using the highly general Autoregressive Integrated Moving Average (ARIMA) framework. The ARIMA model is usually referred to as an ARIMA $(p, d, q)$ since it is composed of $p$ autoregressive terms, $d$ non-seasonal differences (in order to transform a nonstationary stochastic process into a stationary one), and $q$ lagged forecast errors in the prediction equation.

Prices for WCO were obtained from a European broker [18] and price information for palm, canola and soya oils was based off IndexMundi [17]. Fig. 2 depicts the monthly prices for the four feedstocks (palm, canola, soya and WCO) from January 2011 to May 2014 that were used in this study. 


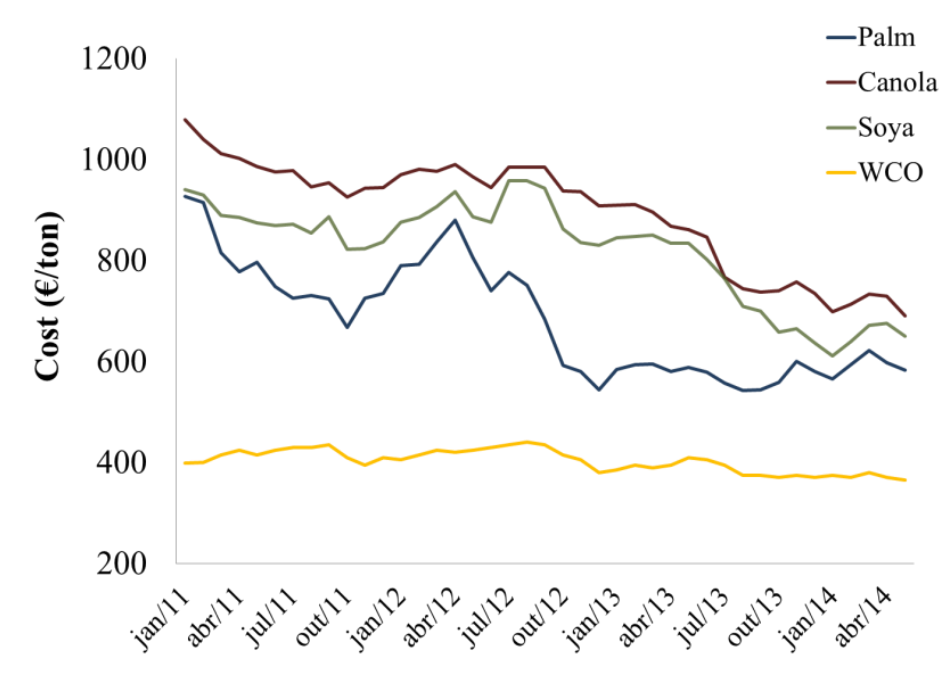

Fig. 2 Monthly prices for palm, canola, soya and WCO

Some fundamental issues for time-series forecasting include (a) determining whether the dataset at hand is trend stationary (e.g., the statistical properties of a process once detrended are constant over time) or difference stationary and (b) incorporating the appropriate number of lags to address serial correlation [57]. One typical approach to address the former issue is to use unit-root tests, where one evaluates whether price shocks tend to be transient or persistent. Should price shocks have a permanent effect on a stochastic process, then its variance diverges towards infinity over time. The fidelity of unit-root tests depend upon the available sample size, which is limited in this particular case. Nevertheless, this study carries out the Augmented Dickey Fuller (ADF) unit-root test for each commodity, which indicated that all time-series are subject to a unit-root and, therefore, should be modeled as difference-stationary processes.

To determine an appropriate lag order for the models we used three separate metrics. First, the overall fit of different lag orders was evaluated using two common goodness-of-fit metrics, the Bayesian Information Criterion (BIC) and the Akaike Information Criterion (AIC) [58]. Additionally, the authors estimated the partial autocorrelation function (PACF) of each dataset to confirm lag orders selected per the BIC and AIC. For each dataset, all three metrics suggested that only one lag order should be incorporated. Further inspection of the residuals suggested that the one 
lag model adequately removed serial correlation from the estimation, an initial concern given the possible presence of seasonality. The structural form of the model selected, $\operatorname{ARIMA}(1,1,0)$, for each dataset is of the form:

$$
\Delta P_{t}=\rho \Delta P_{t-1}+C+\varepsilon_{t}
$$

where $\Delta$ is the first difference operator, $P_{t}$ and $P_{t-1}$ are the prices in month $t$ and $t-1, \rho$ is the autoregressive parameter, $C$ is a constant and $\varepsilon$ is a white noise term that follows a Gaussian distribution with a volatility measure $\sigma$. The model parameters for each feedstock are presented in supplementary material (Section 2). The standard deviation of the predicted price is used in the model to address price volatility.

The adopted model was validated using backcasting [59]. In this technique, a known outcome is compared to the prediction, and the accuracy of the forecast is measured by the Mean Absolute Percent Error (MAPE) according to Equation 14 where $n$ is the number of forecasts [60].

$$
\operatorname{MAPE}=\frac{100 \%}{\mathrm{n}} \sum_{\mathrm{i}=1}^{\mathrm{n}}\left|\frac{\text { Actual }_{i}-\text { Predicted }_{i}}{\text { Actual }_{i}}\right|
$$

Forecasts made from July 2013 to May 2014 were compared to the real prices and a MAPE ranging from 3.4-4.6\% was obtained for the first month predicted and 4.6-6.1\% for the second month predicted.

\subsection{Performance assessment}

To understand the implication of this modeling approach on the attractiveness of WCO to biodiesel producers, the use of WCO in model-suggested blends was assessed using the error rate (ER) and the WCO-blends cost reduction. The error rate (ER) evaluates the blends technical performance and was calculated using posteriori Monte Carlo simulations. The Monte Carlo method statistically simulates random variables, in this case, oil compositions, using pseudo-random numbers [19]. The WCO-blends cost reduction was calculated relatively to equivalent blends (same ER) composed only with virgin oils (VO-blend) using equation (15). 


$$
\text { WCO blend CR }(\%)=\frac{\text { VO blend cost }- \text { WCO blend cost }}{\text { VO blend cost }} * 100
$$

To investigate and interpret the behavior of the proposed approach to address feedstock price uncertainty, two key levels that could be selected by the decision-maker were varied: (a) the extent of available storage capacity and (b) the relative weight placed on price risk (i.e., compared to the expected value of price). Different variants of the model included: (i) a no storage model (No St) obtained by setting StCap equal to zero; (ii) a storage model with no weight on the risk tradeoff parameter, $\alpha$ (i.e., St_ $\alpha=0$ ); (iii) a storage model with four different weights for the risk tradeoff parameter (i.e., $S t_{-} \alpha=1 ; S t_{-} \alpha=3, S t_{-} \alpha=5$ and $S t_{-} \alpha=10$ ). These models assessed the influence of including storage capacity (comparing (i) and (ii)) and the influence of the weight given to the uncertainty term (comparing (ii) with (iii)).

Notably, the results obtained for the No storage model (No St) reflect a hypothetical situation where there is no uncertainty in the prices; the producers buy in each period knowing the exact feedstock price and the quantity necessary to use in that period. Although this situation does not reflect reality, it serves as a useful benchmark against which other model variants can be compared. This formulation also most closely resembles previous work that has examined the application of stochastic optimization to blending-related questions [21].

To test the robustness of the optimization results, we developed two sets of price series - uptrend and downtrend. Each set contains 40 price series each comprising 41 monthly prices. To develop these sets, we first randomly generated 40 simulated historical price datasets for each commodity using the parameter estimates for the $\operatorname{ARI}(1,1)$ model from section 2.2 . In other words, the parameter estimates for $\rho$ and $C$ for each ARI $(1,1)$ model were preserved, but random price shocks were generated to allow the time-series to have behaved in a different stochastic manner over time. This collection of price series represents the downtrend set. Additionally, since all of the raw data 
from which the ARI(1,1) models were developed exhibited a downward stochastic trend over time (see Fig. 2), we generated another 40 simulated historical price data series for each commodity, but now changing the sign of the drift term, $C$, such that it was positive. These price series are referred to as the uptrend set.

To analyze the cost performance of the models, we calculated the average total cost of each model for the uptrend and downtrend sets and the relative difference (RD) of the total cost obtained by two different models. For example, the comparison between the results obtained for the storage model with no weight on the risk tradeoff parameter $\left(S t_{-} \alpha=0\right)$ relatively to the no storage (No St) model was calculated using equation (16).

$$
\mathrm{RD}_{\mathrm{St}_{\alpha}=0 \text { No St }}(\%)=\frac{\text { Total cost }_{\text {St }_{\alpha}=0}-\text { Total }_{\text {cost }} \text { No St }_{\text {St }}}{\text { Total }_{\text {cost }}} * 100
$$

The cost variation performance of the models was assessed through the Mean Absolute Deviation (MAD). This parameter was calculated as the average of the absolute differences obtained between period $p$ and period $p-1$ as given in equation (17).

$$
\mathrm{MAD}=\frac{1}{\mathrm{n}} \sum_{\mathrm{p}=1}^{\mathrm{n}}\left|\mathrm{P}_{\mathrm{p}}-\mathrm{P}_{\mathrm{p}-1}\right|
$$

\section{Results and Discussion}

\subsection{Economic benefits of using Waste Cooking Oil in biodiesel blends}

As an initial assessment of the attractiveness of WCO in blends for biodiesel production, we analyzed a case considering no storage capacity and no price uncertainty $\left(\operatorname{StCap}_{i}=\sigma f c_{i, p}=0\right)$. The optimal blends were obtained for each month (from January 2011 to May 2014) and compared with optimal blends obtained without WCO available. To ensure the comparability of the blends in terms of technical performance, the confidence level was adjusted so that the $E R$ of the blends with and without WCO was similar. In the case when WCO is not available, the confidence level was set to $80 \%$. Conversely, when WCO was available, the confidence level was altered to $90 \%$. Since WCO 
introduces higher compositional uncertainty, the confidence level has to be increased in order to obtain the same technical performance as blends of virgin oils. Fig. 3 depicts the blends composition obtained when WCO is not available (left-hand side top) and when it is (right-hand side top). The dashed line in the graph (right-hand side down) is the $E R$ of the blends and the solid line is the cost reduction obtained relatively to the equivalent blend (obtained in the same month and with similar $E R$ ) with no WCO available.

Using WCO in blends for biodiesel production allows a cost reduction relative to blends without WCO that ranges from $1 \%$ to $10 \%$. This reduction is related to the WCO quantity in the blend and the relation among the feedstock prices. From January 2011 to August 2012, the virgin oils price is closer to each other relative to the WCO price and in this period the optimal blends are mainly composed of canola and WCO. From September 2012 to September 2013, there is a reduction on the palm oil price relatively to soya and canola oils price and the optimal blends of these months contain a higher quantity of palm and a lower quantity of WCO. Consequently, the cost reduction relatively to virgin oils blends in this period is lower.

To analyze the influence of different price trajectories, we used the 40 price series that were simulated based on historical data. On average, a cost reduction of $7 \%$ is achieved when WCO is available to blend. Nevertheless, one should point out that in some of these simulated series the WCO price can be in some periods higher than the virgin oils. For the cases when WCO price is always the lower along the series, the cost reduction varies from about $6 \%$ to $23 \%$. This variation is because the relation among the feedstock prices is different. 

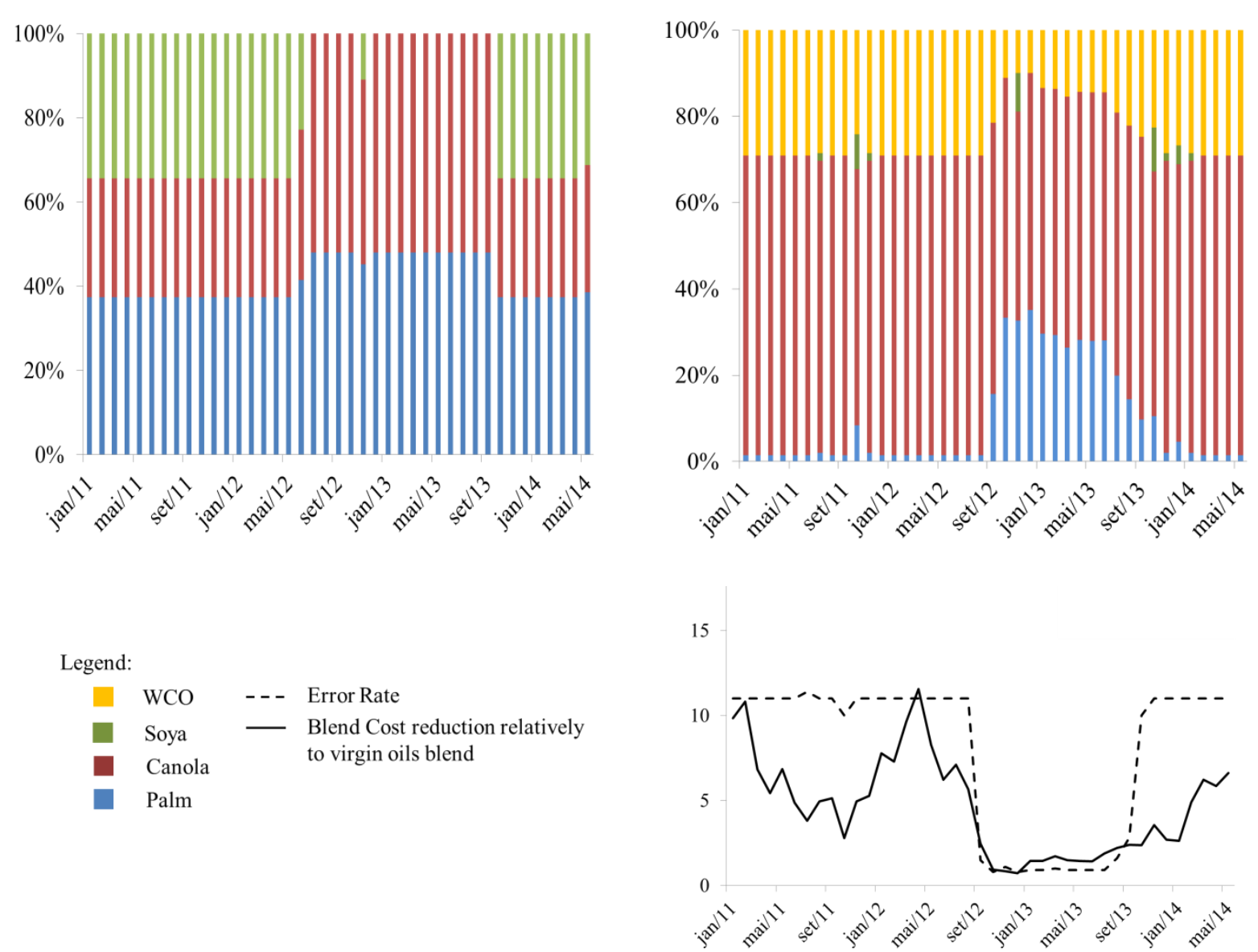

Fig. 3 Blend composition for each month from January 2011 to May 2014 without WCO available (left-hand side top) and with WCO available (right-hand side top). Error rate of the blends and blend cost reduction (left hand-side down)

\subsection{Managing cost and cost variation addressing feedstock price and composition uncertainty}

The different models described in Section 2.3 were used to evaluate the proposed modeling strategy particularly as a function of two key aspects selected by the decision-maker: the extent of available storage capacity and the relative weight placed on price risk (i.e. compared to the expected value of price). The compositional uncertainty is considered with a confidence level fixed to 95\%, allowing a $5 \%$ probability of non-compliance for each property.

\subsubsection{Influence of planned hedging purchases informed by forecasted feedstock prices on cost variation}

The different models were tested on each data set. The average total cost and the average MAD of the 80 data sets were calculated and are depicted in Fig. 5 (left-hand side), together with the 
inventory level (right-hand side). The results obtained for the No storage model (No St) reflect the situation where there is no uncertainty in the prices; the producers buy in each period knowing the exact feedstock price and the quantity necessary to use in that period. Although this situation does not reflect reality it can be considered as an ideal situation benchmark against which the other formulations can be compared.

Results in Fig. 4 show that when storage capacity is added to the model (blue dots) there is a cost reduction relatively to the idealized no storage case (red cross). When storage is available, there is a tradeoff between the cost variation and the total cost. Lower average cost solutions are obtained if no or little weight is given to the risk tradeoff parameter $\alpha$ (solutions St_ $\alpha=0$, St_ $\alpha=1$ ) but these solutions present higher cost variation (approximately 85\%). If one intends to reduce cost variation, the weight of the risk tradeoff parameter has to be increased. The minimum cost variation (MAD= $20 \%$ ) was obtained for $\alpha=10$. Interestingly, for this case, there is a $75 \%$ reduction in cost variation with only a less than $1 \%$ increase in average cost. This tradeoff may be attractive for many producers and is possible through the combination of models presented here. From the second plot in Fig. 4 (Fig. 4, right-hand side), it is clear that the reduction of cost variation (obtained with increasing $\alpha$ ) results from an increase of the inventory level suggested by the model. It should be noted that for $\alpha=10$, the cost variation is the closest we could obtain to the ideal situation of the No storage scenario. The results obtained for $\alpha$ higher than 10 show no reduction in the MAD average value or spread. 

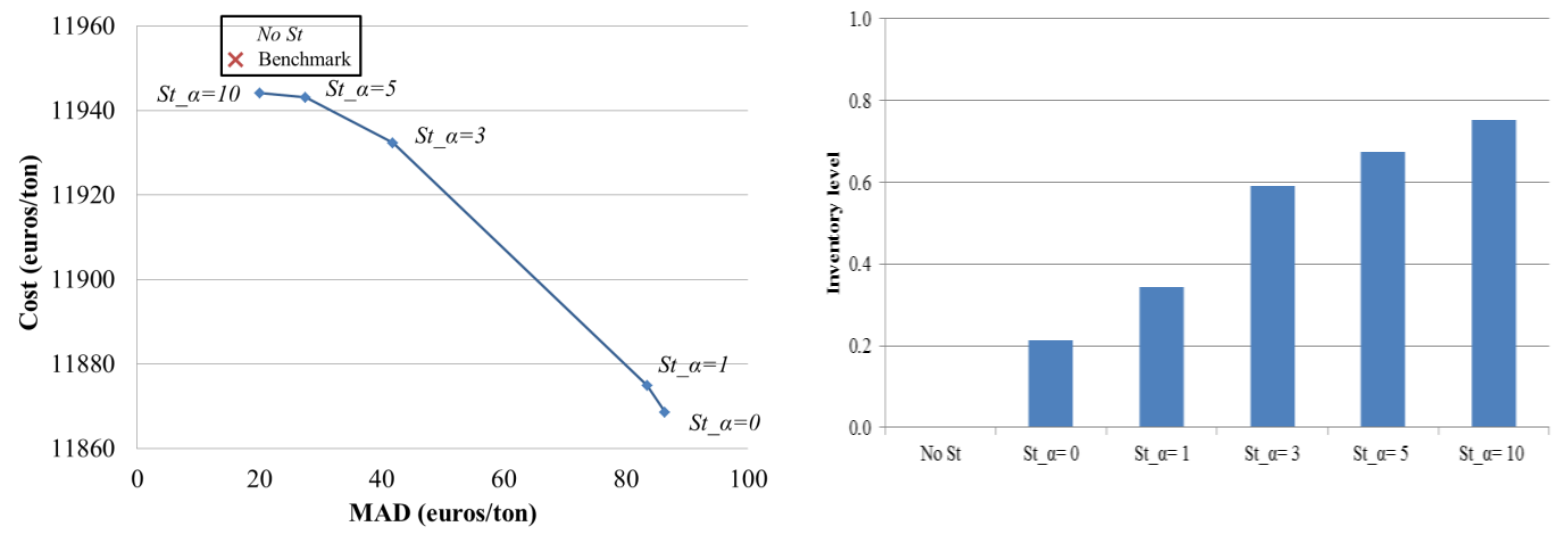

Fig. 4 - Average total cost vs average MAD for the 80 data sets (left-hand side) and inventory level (right-hand side) obtained for each model. No St: No Storage; St_ $\alpha$ : Storage available and risk tradeoff $\alpha=0,1,3,5$ and 10.

To better understand the implications of the model, we disaggregate the results and analyze separately the behavior for the uptrend and downtrend data sets. The results for the uptrend and downtrend (average total cost vs average MAD) are presented in Fig. 5 and the average inventory level is showed in Fig. 6. Individual plots of average total cost and Box-and-Wiskers of the MAD are provided in supplementary material.
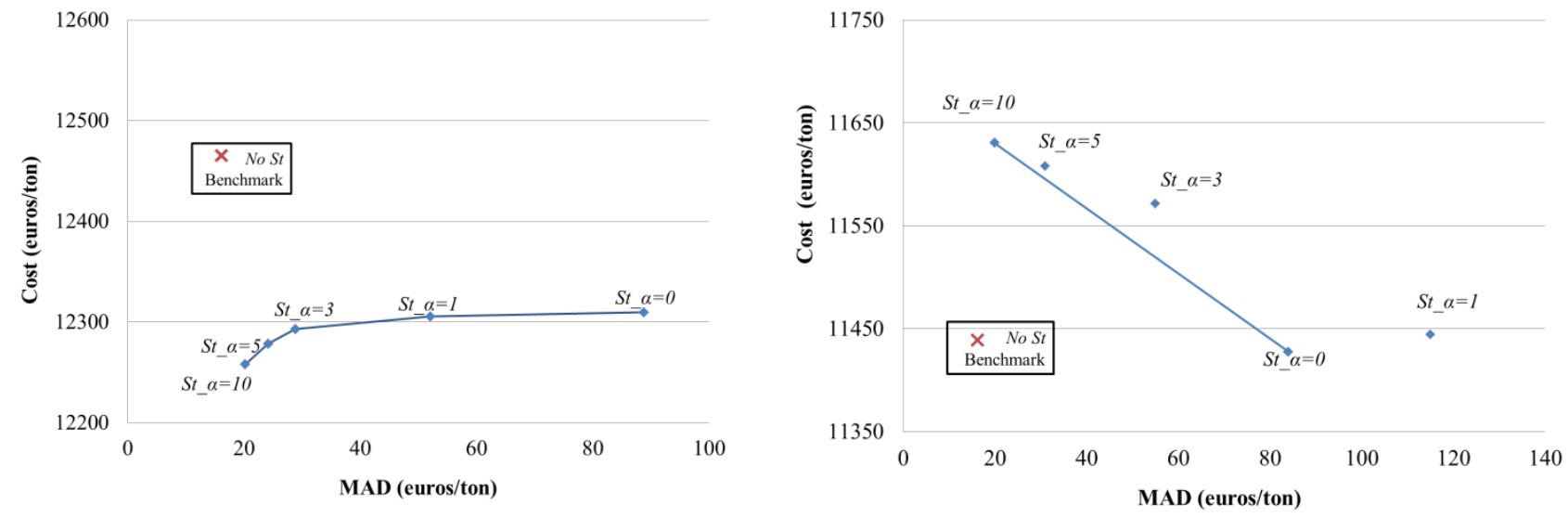

Fig. 5 - Cost vs MAD obtained for the different models, for the uptrend (left-hand side) and downtrend (right-hand side) data sets. No St: No Storage; St_ $\alpha$ : Storage available and risk tradeoff $\alpha=0,1,3,5$ and 10. 

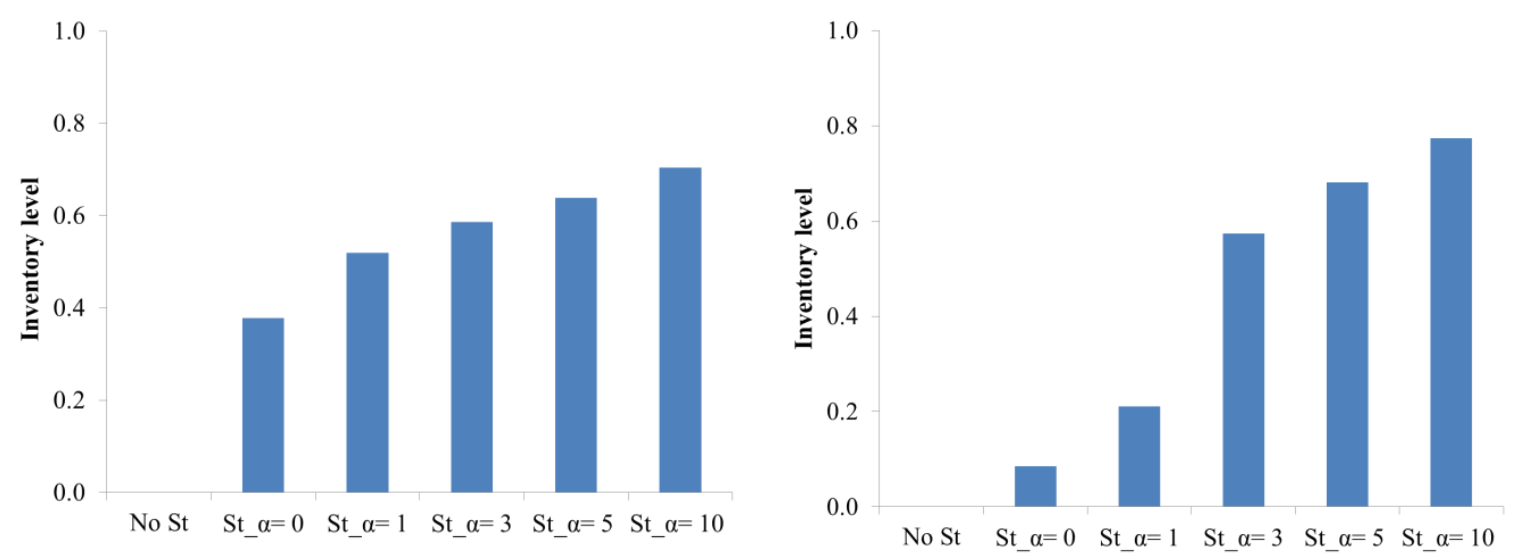

Fig. 6- Inventory level obtained for the different models, for the uptrend (left-hand side) and downtrend (right-hand side) data sets. No St: No Storage; St_ $\alpha$ : Storage available and risk tradeoff $\alpha=0,1,3,5$ and 10.

A common observation can be made from the results obtained either aggregated (Fig. 4) or separated according data set trends (Fig. 5): when storage capacity is added to the model (a more realistic situation) and if no weight is given to the risk tradeoff parameter $\left(S t \_\alpha=0\right)$ the cost variation is significantly higher than the idealized No St case. A reduction on the cost variation is observed with increasing weight given to the uncertainty term (increasing $\alpha$ ) and for $\alpha=10$, the cost variation is the closest we could obtain to the idealized case of the No storage scenario.

Nevertheless, the results average total cost versus average MAD obtained by the different models present distinct profiles depending on the price trend. We observed that when prices are generally increasing (uptrend - left-hand plot of Fig. 5) average costs are higher when no storage is available (No St) compared some amount of storage is available (St_ $\left.\alpha=0 \ldots \mathrm{St} \_\alpha=10\right)$. Furthermore, when more weight is given to price risk (increasing $\alpha$ ) average inventory grows (uptrend - left-hand plot of Fig. 6) and average cost drops; in the uptrend, clever inventory purchases can lead to savings, avoiding a purchase later at higher cost. In this case, there is no tradeoff between costs and cost variation: lower cost variation can be obtained at a lower cost.

Interestingly, in the downtrend case (right-hand plot of Fig. 5) there is a small drop in average cost when comparing the model that has no storage capacity (No St) to the model with storage capacity without considering the uncertainty $\left(S t_{-} \alpha=0\right)$ and, contrary to what was observed for the uptrend, 
the total average cost increases as the alpha parameter rises. Increasing alpha places more emphasis on reducing cost risk and there is a tradeoff between costs and cost variation. This, in turn, drives up average inventory (right-hand plot of Fig. 6). For the downtrend cases, purchases for inventory are on average more expensive than deferred purchases.

Average cost reductions are observed when comparing the model that has no storage capacity (No $S t)$ to the model with storage capacity without considering the uncertainty $(S t \alpha=0)$ for both price trends: about $1.25 \%$ for the uptrend and $0.16 \%$ for the downtrend. Despite the fact that these results were obtained for a storage cost of zero, the sensitivity analyses performed on the storage cost parameter considering it up to $3 \%$ of the feedstock portfolio price ( $15 € /$ ton), show the same type of behavior of the models. Nevertheless, the cost reductions obtained are lower: about $0.8 \%$ for the uptrend and about $0.07 \%$ for the downtrend.

\subsubsection{Influence of the approach in the attractiveness of WCO}

The previous section shows that planned hedging purchases informed by forecasted feedstock prices can lead to production cost variation reductions., To analyze the effect on the WCO use of the suggested approach and also if WCO would present benefits not only in terms of costs (as it was shown in section 3.1) but also in the cost variation, we calculated the average WCO level for each model (with increasing $\alpha$ ) and the MAD for the different models and data sets setting the WCO quantity in the blends to zero.

As WCO price presents lower variability compared to the virgin oils, we did observe an increase in the WCO level with increasing the risk tradeoff parameter but not very significant (about $3 \%$ increase comparing $\alpha=10$ relatively to $\alpha=0)$. This is because the standard deviation of the WCO forecasted price (that is used in the third term of equation 3 that penalizes the use of feedstocks that increase future price uncertainty) is very close to the standard deviation of the palm forecasted price and this feedstock price is also very often closer to the WCO price (sometimes is even lower) in the simulated data sets. In what concerns the use of WCO or not in the blends and its effect on the cost 
variation, we observed that results of MAD median values and spread are lower when WCO is available relatively to the case when only virgin oils are used. The Box-and-Whisker plot of the MAD of both cases are provided in supplementary material.

\section{Application in Real-world facilities}

Results of these case analyses suggests that real-world facilities could benefit from the application of stochastic programming models, like those described here, to improve production planning decisions. Depending on the context, facilities applying these models may be able to reduce feedstock costs, maintain more stable costs, and/or diversify their feedstock supply chain while still meeting their current product quality requirements.

The first step towards realizing these benefits is data management. The models described here depend upon accurate and current data. There are two primary roles for that data in the models. First is data to relate feedstock cost to feedstock properties. Second is historical data of feedstock price movement. For purchased feedstocks, firms should develop a database of feedstock properties and purchase price. Firms should also collect data on prices of other feedstocks even if they are not purchasing them at the time.

Using the data on feedstock properties, firms can estimate the distribution of properties (particularly $\mu_{i}$ and $\sigma_{i}$ from equation 2) for a given feedstock. Using the historic data on feedstock prices, firms can develop the ARIMA projection models. The distributional information and projection models should be updated annually. Firms may want to consider recalibrating the parameters that relate feedstock properties to expected fuel properties as well, but this not need to be revised frequently. Using these firm specific data and models proposed here, firms could then develop monthly purchasing plans that should improve their financial performance in the long run. 


\section{Conclusions}

A stochastic programming model was developed to support production planning decisions to reduce cost and cost variation in biodiesel production. The model simultaneously addresses operational (using the chance-constrained formulation) and feedstock price uncertainty (using time series analysis to forecast the feedstock price). Technical, cost and cost variation performance metrics were used to investigate and interpret the behavior of the proposed approach.

The proposed stochastic programming formulation proved to be useful in determining optimum planning for feedstocks acquisition, blending and storage that minimize the risks associated with feedstock price fluctuations. If feedstock prices present an uptrend behavior the suggested optimization approach also allows the biodiesel producer to obtain a cost reduction.

Results show that addressing the compositional uncertainty using the chance-constrained formulation allows the use of feedstocks with high compositional uncertainty like waste cooking oils in biodiesel blends without compromising the biodiesel technical performance. A cost reduction was obtained for blends with waste cooking oils relatively to blends composed only of virgin oils. This cost reduction depends on the relation among the prices of the feedstocks. The use of low-cost feedstocks in a diversified portfolio of raw materials used in blending optimization models represents a cost reduction opportunity for the biodiesel producer without compromising the biodiesel quality. As for the influence on cost variation, although the lower price volatility of the waste cooking oils should be favored by the recourse model, the various compositional constraints limit flexibility enough that it does not appear to be realized significantly for this set of feedstocks, prices, and technology. As waste cooking oils present lower environmental impacts relatively to the virgin oils its use in the blends also represents a chance for biodiesel producers to move towards a more sustainable production

One must highlight that this model can be adapted to any country specific biodiesel quality standard. Although, the technical constraints thresholds used to illustrate the model are based on European regulation they can be adapted to other standards (for example in the US regulation there 
is no threshold for iodine value and there is a lower limit for oxidative stability. Moreover, it can also be used to support the assessment of the use of fatty acid based residue-derived feedstocks like for example animal fats or the viability of emerging feedstocks such as algae.

\section{ACKNOWLEDGEMENTS}

Carla Caldeira acknowledges financial support from the Portuguese Science and Technology Foundation (FCT) through grant SFRH/BD/51952/2012. Financial support from the Portuguese Science and Technology Foundation (FCT) projects: FEDER/FCT | PTDC/AGR-FOR/1510/2014 (POCI-01-0145-FEDER-016764); FEDER/FCT | PTDC/AAG-MAA/6234/2014 (POCI-01-0145FEDER-016765. The research presented in this article was developed under the framework of the Energy for Sustainability Initiative of the University of Coimbra and the MIT Portugal Program.

\section{References}

[1] Tyner WE. Policy Alternatives for the Future Biofuels Industry. J Agric Food Ind Organ 2007;5. doi:doi.org/10.2202/1542-0485.1189.

[2] Chen S, Kuo H, Chen C. Modeling the relationship between the oil price and global food prices. Appl Energy 2010:2517-25.

[3] Demirbas A. Political, economic and environmental impacts of biofuels: a review. Appl Energy 2009:S108-17. doi:doi:10.1016/j.apenergy.2009.04.036.

[4] Plevin RJ, O'Hare M, Jones AD, Torn MS, Gibbs HK. Greenhouse gas emissions from biofuels' indirect land use change are uncertain but may be much greater than previously estimated. Environ Sci Technol 2011;15:338-51.

[5] Huo H, Wang M, Bloyd C. Life-cycle assessment of energy use and greenhouse gas emissions of soybean-derived biodiesel and renewable fuels. Environ Sci Technol $2008 ; 43: 750-6$. 
[6] Haas MJ, McAloon AJ, Yee WC, Foglia T. A process model to estimate biodiesel production costs. Bioresour Technol 2006;97:671-8. doi:10.1016/j.biortech.2005.03.039.

[7] Malça J, Coelho A, Freire F. Environmental Life-Cycle Assessment of Rapeseed-Based Biodiesel: Alternative Cultivation Systems and Locations. Appl Energy 2014;114:837-44. doi:10.1016/j.apenergy.2013.06.048.

[8] European Comission. Directive 2015/1513 of the European Parliament and of the Council. Off J Eur Union 2015;2014:20-30. doi:http://eurlex.europa.eu/pri/en/oj/dat/2003/1_285/1_28520031101en00330037.pdf.

[9] Elliott K. Biofuel Policies : Fuel versus Food, Forests , and Climate CGD Policy Paper 051 January 20152015.

[10] ICCT. Final EPA rule for renewable fuel standard 2014 - 2016 volumes, The international council on clean transportation (ICCT). Int Counc Clean Transp Policy Updat 2015.

[11] Kotrba R. Low-Cost Biodiesel Production. Biodiesel Mag 2014.

[12] Talebian-Kiakalaieh A, Amin N, Mazaheri H. A review on novel processes of biodiesel production from waste cooking oil. Appl Energy 2013:683-710.

[13] Dufour J, Iribarren D. Life cycle assessment of biodiesel production from free fatty acid-rich wastes. Renew Energy 2012;38:155-62. doi:10.1016/j.renene.2011.07.016.

[14] Caldeira C, Queirós J, Freire F. Biodiesel from Waste Cooking Oils in Portugal: alternative collection systems. Waste and Biomass Valorization 2015;6:771-9. doi:http://dx.doi.org/10.1007/s12649-015-9386-z.

[15] Smith H, Winfield J, Thompson L. The market for biodiesel production from used cooking oils and fats, oils and greases in London. LRS Consult 2013.

[16] Knothe G, Steidley KR. A comparison of used cooking oils: A very heterogeneous feedstock for biodiesel. Bioresour Technol 2009;100:5796-801. doi:10.1016/j.biortech.2008.11.064.

[17] IndexMundi. http://www.indexmundi.com/ 2014. http://www.indexmundi.com/ (accessed May 19, 2014). 
[18] Grennea. Overview of the European double-counting markets and market perspectives 2014.

[19] Gaustad G, Li P, Kirchain R. Modeling methods for managing raw material compositional uncertainty in alloy production. Resour Conserv Recycl 2007;52:180-207. doi:10.1016/j.resconrec.2007.03.005.

[20] Olivetti, Elsa; Gaustad, Gabrielle G.; Fiels, Frank R.; Kirchain RE. Increasing Secondary and Renewable Material Use: A Chance Constrained Modeling Approach to Manage Feedstock Quality Variation. Environ Sci Technol 2011;45:4118-26.

[21] Gülşen E, Olivetti E, Freire F, Dias L, Kirchain R. Impact of feedstock diversification on the cost-effectiveness of biodiesel. Appl Energy 2014;126:281-96. doi:10.1016/j.apenergy.2014.03.063.

[22] Olivetti E, Gülşen E, Malça J, Castanheira E, Freire F, Dias L, et al. Impact of policy on greenhouse gas emissions and economics of biodiesel production. Environ Sci Technol 2014;48:7642-50. doi:10.1021/es405410u.

[23] Hoekman SK, Broch A, Robbins C, Ceniceros E, Natarajan M. Review of biodiesel composition, properties and specifications. Renew Sustain Energy Rev 2012;16:143-69. doi:10.1016/j.rser.2011.07.143.

[24] Vatani B, Chowdhury B, Dehghan S, Amjady N. A critical review of robust self-scheduling for generation companies under electricity price uncertainty. Int J Electr Power Energy Syst 2018;97:428-39. doi:10.1016/j.ijepes.2017.10.035.

[25] Gligoric Z, Gligoric M, Dimitrijevic B, Grozdanovic I, Milutinovic A, Ganic A, et al. Model of room and pillar production planning in small scale underground mines with metal price and operating cost uncertainty. Resour Policy 2018:1-9. doi:10.1016/j.resourpol.2018.07.011.

[26] Zheng S, Chen S. Fleet replacement decisions under demand and fuel price uncertainties. Transp Res Part D Transp Environ 2015;60:153-73. doi:10.1016/j.trd.2016.09.001.

[27] Calfa BA, Grossmann IE. Optimal procurement contract selection with price optimization 
under uncertainty for process networks. Comput Chem Eng 2015;82:330-43. doi:10.1016/j.compchemeng.2015.07.015.

[28] Jahani H, Abbasi B, Alavifard F, Talluri S. Supply chain network redesign with demand and price uncertainty. Int J Prod Econ 2018;205:287-312. doi:10.1016/j.ijpe.2018.08.022.

[29] Rakotoarison H, Loisel P. The Faustmann model under storm risk and price uncertainty: A case study of European beech in Northwestern France. For Policy Econ 2017;81:30-7. doi:10.1016/j.forpol.2017.04.012.

[30] Al-Othman WBE, Lababidi HMS, Alatiqi IM, Al-Shayji K. Supply chain optimization of petroleum organization under uncertainty in market demands and prices. Eur J Oper Res 2008;189:822-40. doi:10.1016/j.ejor.2006.06.081.

[31] Khor CS, Elkamel A, Ponnambalam K, Douglas PL. Two-stage stochastic programming with fixed recourse via scenario planning with economic and operational risk management for petroleum refinery planning under uncertainty. Chem Eng Process Process Intensif 2008;47:1744-64. doi:10.1016/j.cep.2007.09.016.

[32] Lin CC, Wu YC. Combined pricing and supply chain operations under price-dependent stochastic demand. Appl Math Model 2014;38:1823-37. doi:10.1016/j.apm.2013.09.017.

[33] Chen R, Deng T, Huang S, Qin R. Optimal crude oil procurement under fluctuating price in an oil refinery. Eur J Oper Res 2015;245:438-45. doi:10.1016/j.ejor.2015.03.002.

[34] Moradi MH, Eskandari M. A hybrid method for simultaneous optimization of DG capacity and operational strategy in microgrids considering uncertainty in electricity price forecasting. Renew Energy 2014;68:697-714. doi:10.1016/j.renene.2014.03.001.

[35] Alex Marvin W, Schmidt LD, Benjaafar S, Tiffany DG, Daoutidis P. Economic Optimization of a Lignocellulosic Biomass-to-Ethanol Supply Chain. Chem Eng Sci 2012;67:68-79. doi:10.1016/j.ces.2011.05.055.

[36] Dal-Mas M, Giarola S, Zamboni A, Bezzo F. Strategic design and investment capacity planning of the ethanol supply chain under price uncertainty. Biomass and Bioenergy 
2011;35:2059-71. doi:10.1016/j.biombioe.2011.01.060.

[37] Giarola S, Bezzo F, Shah N. A risk management approach to the economic and environmental strategic design of ethanol supply chains. Biomass and Bioenergy 2013;58:31-51. doi:10.1016/j.biombioe.2013.08.005.

[38] Mazzetto F, Ortiz-Gutiérrez RA, Manca D, Bezzo F. Strategic design of bioethanol supply chains including commodity market dynamics. Ind Eng Chem Res 2013;52:10305-16. doi:10.1021/ie401226w.

[39] Osmani A, Zhang J. Economic and environmental optimization of a large scale sustainable dual feedstock lignocellulosic-based bioethanol supply chain in a stochastic environment. Appl Energy 2014;114:572-87. doi:10.1016/j.apenergy.2013.10.024.

[40] Santibañez-Aguilar JE, Morales-Rodriguez R, González-Campos JB, Ponce-Ortega JM. Stochastic design of biorefinery supply chains considering economic and environmental objectives. J Clean Prod 2016;136:224-45. doi:10.1016/j.jclepro.2016.03.168.

[41] Zhang Y, Jiang Y. Robust optimization on sustainable biodiesel supply chain produced from waste cooking oil under price uncertainty. Waste Manag 2017;60:329-39. doi:10.1016/j.wasman.2016.11.004.

[42] Bairamzadeh S, Saidi-Mehrabad M, Pishvaee MS. Modelling different types of uncertainty in biofuel supply network design and planning: A robust optimization approach. Renew Energy 2018;116:500-17. doi:10.1016/j.renene.2017.09.020.

[43] Khishtandar S. Simulation based evolutionary algorithms for fuzzy chance-constrained biogas supply chain design. Appl Energy 2019;236:183-95. doi:10.1016/j.apenergy.2018.11.092.

[44] Charnes A, Cooper W. Chance-constrained programming. Manage Sci 1959;6:73-9.

[45] Sahinidis N V. Optimization under uncertainty: state-of-the-art and opportunities. Comput Chem Eng 2004;28:971-83. doi:10.1016/j.compchemeng.2003.09.017.

[46] Kampempe JDB. Chance-Constrained Approaches for Multiobjective Stochastic Linear 
Programming Problems. Am J Oper Res 2012;02:519-26. doi:10.4236/ajor.2012.24061.

[47] Giakoumis EG. A statistical investigation of biodiesel physical and chemical properties, and their correlation with the degree of unsaturation. Renew Energy 2013;50:858-78. doi:10.1016/j.renene.2012.07.040.

[48] Refaat AA. Correlation between the chemical structure of biodiesel and its physical properties. Int J Environ Sci Technol 2009;6:677-94. doi:10.1007/BF03326109.

[49] Bamgboye AI, Hansen AC. Prediction of cetane number of biodiesel fuel from the fatty acid methyl ester ( FAME ) composition. Int Agrophysics 2008:21-9.

[50] Ramos MJ, Fernández CM, Casas A, Rodríguez L, Pérez A. Influence of fatty acid composition of raw materials on biodiesel properties. Bioresour Technol 2009;100:261-8. doi:10.1016/j.biortech.2008.06.039.

[51] CEN. EN 14214: automotive fuels - fatty acid methyl esters (FAME) for diesel engines requirements and test methods. 2008.

[52] Park J-Y, Kim D-K, Lee J-P, Park S-C, Kim Y-J, Lee J-S. Blending effects of biodiesels on oxidation stability and low temperature flow properties. Bioresour Technol 2008;99:1196203. doi:10.1016/j.biortech.2007.02.017.

[53] Caldeira C, Freire F, Olivetti EA, Kirchain R. Fatty acid based prediction models for biodiesel properties incorporating compositional uncertainty. Fuel 2017;196:13-20. doi:10.1016/j.fuel.2017.01.074.

[54] Caldeira C, Gülsen E, Olivetti EA, Kirchain R, Dias L. A Multiobjective Model for Biodiesel Blends Minimizing Cost and Greenhouse Gas Emissions. In: Murgante B. et al. (eds) Computational Science and Its Applications - ICCSA 2014. Lect Notes Comput Sci 2014;8581:653-66. doi:10.1007/978-3-319-09150-1_48.

[55] GAMS. GAMS Development Corporation: General Algebraic Modeling System (GAMS) Release 23.7.3 Washington, DC, USA 2011.

[56] Arne D. CONOPT. ARKI Consult Dev A/S, Bagsvaerd, Denmark 2014. 
http://www.conopt.com/ (accessed March 1, 2014).

[57] Chatfield C. The Analysis of Time Series: An Introduction. 2003.

[58] Liew VKS. Which Lag Lenght Selection Criteria Should We Emply? Econ Bull 2004:1-9.

[59] McDowall W and ME. Forecasts, Scenarios, Visions, and Backcasts and Roadmaps to the Hydrogen Economy. Policy Stud Inst London, UK 2004.

[60] Armstrong JS. Principles of Forecasting: A Handbook for Researchers and Practitioners. Kluwer Academic Publishers; 2001. 